\title{
The experimental validation of a numerical model for the receptance prediction
}

\author{
A. ZOUGARI ${ }^{1}$, J. MARTÍNEZ ${ }^{2}$ \\ 1. 2. Mechanical Engineering Department. Universitat Politécnica de Catalunya. Av. Diagonal 647, 08028 Barcelona, \\ Spain.ayoub.zougari@gmail.com,jmartinez.miralles@upc.edu
}

\begin{abstract}
The traditional ballasted track with wooden sleepers covers today most railway lines constructions, including the tracks of tram and metro or the industrial railway branching. In this work, we present an experimental methodology to validate a numerical model based on finite element method, the model was previously well defined using the ANSYS Parametric Design Language (APDL) and adapted to represent a classical ballasted track. The obtained result of the analysis is expressed as a frequency response of the track and it is compared to the experimental result from measurements made on the metropolitan classical railway track of Barcelona.
\end{abstract}

\section{Keywords : Numerical model, vibration}

response, frequency response, experimental

result.

\section{Introduction}

One of the main difficulties to be considered when planning a new railway line is the impact of noise and vibrations on the surrounding areas. This influence is particularly visible in urban railway lines, where the prime disadvantage on the surface is air-borne noise emission, while in the metro it is ground-borne vibrations that cause more problems to residents living near the railway lines [1].

The Mechanical Engineering Department (DEM) of the Polytechnic University of Catalonia regularly cooperates with the company of the Metropolitan Railway of Barcelona (FCMB). This cooperation have carried out the development of monitoring techniques for the control of the train wheels condition, and created a system that allows us to determine when it is necessary to change one or more track elements. For this reason, it is a question of adjusting as much as possible the life service of the element and, after all, of controlling the vibrations level transmitted to the environment [2, 3, 4]. In this work, an experimental methodology is presented in order to validate a numerical model based on finite elements method (FEM) and developed with APDL (Figure 1), the numerical model of the classical ballasted track can study the interaction between rails, and it is designed to characterize the mechanism of vibration generation. In this study, the frequency response of the track was defined and evaluated by the numerical data in comparison with experimental measurements $[5,6,7]$.

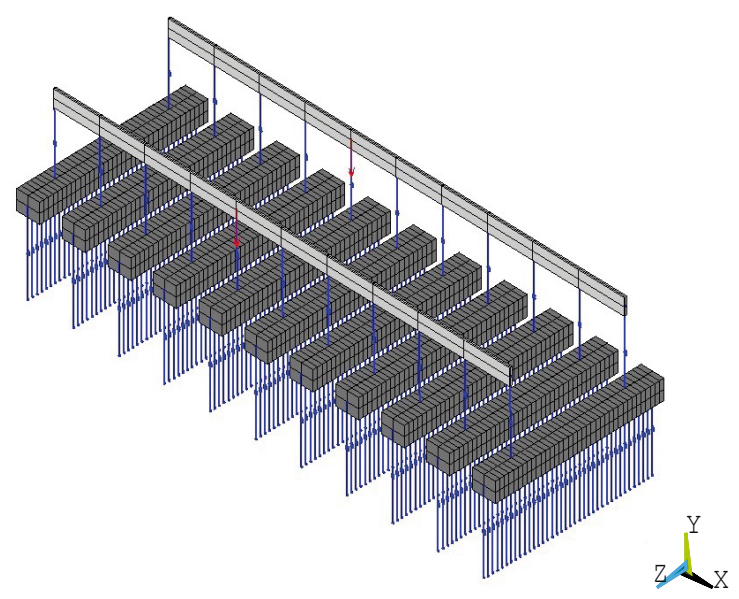

Fig.1. Numerical model of the classical ballasted track with wooden sleepers.

\section{The experimental methodology to obtain the frequency response of the track}

The vibrations measurements are a fundamental part in studying the causes of vibrations in mechanical systems. The experimental data obtained from the measurements are used to characterize the vibratory behavior of these systems, determine their dynamic parameters and validate the numerical models used for their study, as in the case of this work. Considering the advantages mentioned in a previous article [8], we have chosen the best method for the experimental determination of the frequency response. Firstly the studied track is excited with an increasing harmonic force, therefore the vibration signal is captured at different locations. The relationship between the recorded signals and the excitation for each frequency provides the frequency response functions (FRF).

Figure 2 shows a scheme graphic in which are included all the used components in the implementation of the chosen experimental method. 


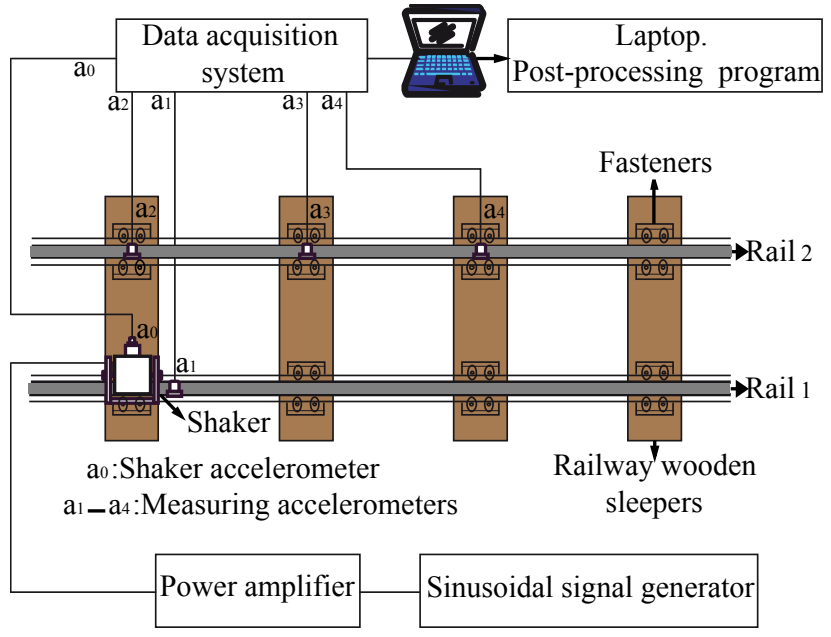

Fig.2. The implemented scheme on a traditional ballasted track with wooden sleepers.

Usually, the structure is equipped with one or more accelerometers or other sensors to measure the response of the structural element ( 5 accelerometers have been used in this work), while the excitation force is applied to one of the rails. For this reason, an electrodynamic shaker has been used, attached to the head of the rail by means of a fastening plate with clamps (figure 3).

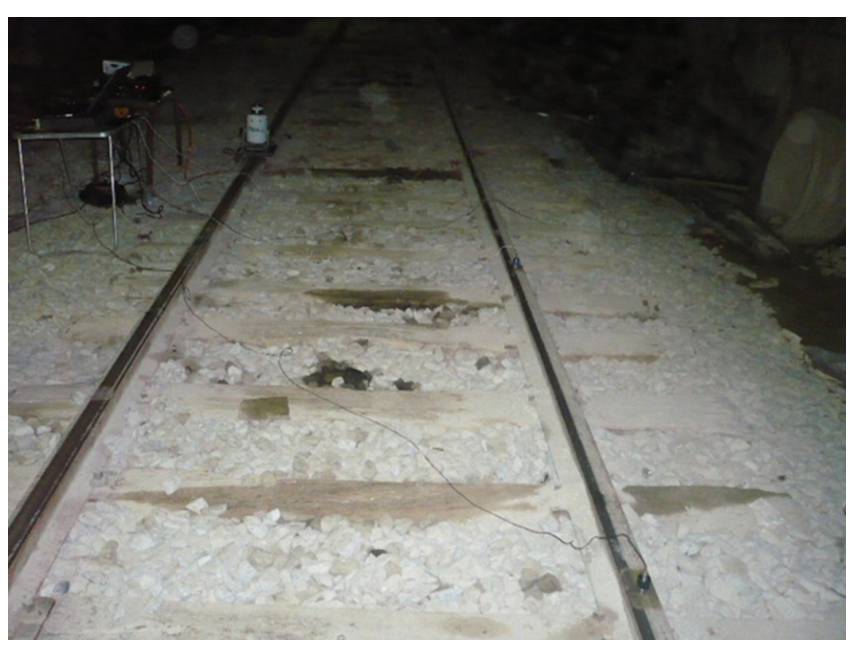

Fig 3. Straight stretch of the classical ballasted track in FCMB.

The shaker has been placed above a sleeper. The amplifier that powers the shaker is controlled by a sinusoidal signal generator with adjustable frequency. A mass of $2 \mathrm{~kg}$ is fastened to the mobile base of the shaker so that, when vibrating, it generates the harmonic exciting force that is transmitted to the rail through the fastening plate. The captured signals by the ICP accelerometers are transmitted to the data acquisition system. A multi-channel data acquisition system has been used, which digitizes all the signals simultaneously and stores them in the computer hard disk, where different types of treatment are performed to obtain all the information needed to analyze and monitor vibrations of the studied track. The vibration signals for frequencies between 20 and $400 \mathrm{~Hz}$ have been recorded, in the frequency band of interest. Finally, the information has been treated with applications developed in the Vibrations Laboratory of DEM using MATLAB. These applications have been used for the assessment of the receptance at the point of excitation and the cross receptances between the point of excitation and any other accelerometer location on the railway track. The magnitude of the exciting force has been determined from the signals provided by two accelerometers, the first is fixed to the vibrating mass and the second to the rail next to the actuator.

\section{Comparison of the numerical result with the experimental measurements}

To ascertain the validity of the track numerical model, the track frequency responses provided by the numerical model have been contrasted with experimental measurements. The considered parameters in the comparison are as shown in the next table. The comparison analysis is made in the frequency domain by means of the rail vertical receptance, which expresses the vertical displacement of the rail, $y_{\mathrm{c}}$, in a certain location as a function of the harmonic vertical force, $F$, applied at the same -or different- location, for each frequency $f$. The receptance equation is :

$$
\begin{aligned}
R(f) & =\frac{y_{\mathrm{c}}(f)}{F(f)} \\
\text { With } \quad F(f)=F e^{j 2 \pi f t} ; y_{\mathrm{c}}(f) & =y_{\mathrm{c}} e^{j(2 \pi f t+\varphi)}
\end{aligned}
$$

Where $y_{\mathrm{c}}$ is the amplitude of the rail vertical displacement, $F$ is the amplitude of the vertical harmonic force applied to the rail, and $\varphi$ is the receptance phase

Table 1. Parameter values used in the experimental validation.

\begin{tabular}{|c|c|}
\hline International rail gauge & $1,435 \mathrm{~m}$ \\
\hline \multicolumn{2}{|c|}{ Rail UIC 54 } \\
\hline \multicolumn{2}{|c|}{$0,6 \mathrm{~m}$} \\
\hline Mass of rail beam per unit length & $54,4 \mathrm{~kg} / \mathrm{m}$ \\
\hline Density of steel & $7850 \mathrm{~kg} / \mathrm{m}^{3}$ \\
\hline Young's modulus of steel & $210 \mathrm{GPa}$ \\
\hline Poisson's ratio of steel & 0,3 \\
\hline Rail cross-sectional area & $6,93 \cdot 10^{-3} \mathrm{~m}^{2}$ \\
\hline Rail second moment of area & $2,35 \cdot 10^{-5} \mathrm{~m}^{4}$ \\
\hline Rail loss factor & 0,02 \\
\hline Traditional ballasted track with timber sleepers \\
\hline Length of sleepers & $2,4 \mathrm{~m}$ \\
\hline Mass of sleepers & $90 \mathrm{~kg}$ \\
\hline Young's modulus of wooden sleepers & $10 \mathrm{GPa}$ \\
\hline Width x height of the sleepers & $0,22 \mathrm{~m} \mathrm{x} 0,12 \mathrm{~m}$ \\
\hline Rail pad stiffness & $\mathrm{Rigid}$ \\
\hline Rail pad loss factor & 0,1 \\
\hline Ballast stiffness & $33,8 \mathrm{MN} / \mathrm{m}$ \\
\hline Loss factor of ballast & 0,24 \\
\hline
\end{tabular}


All the track components have been described using different elements of the ANSYS library [9]. The boundary conditions are identical to the ones used in the numerical models for different types of tracks [8]. Figure 4 shows the comparison between receptances obtained experimentally and those calculated numerically, both at the point where the exciting force was applied. As to the calculations, the same frequency range has been taken into account, a frequency resolution of $10 \mathrm{~Hz}$ from $20 \mathrm{to} 400 \mathrm{~Hz}[4,7]$.

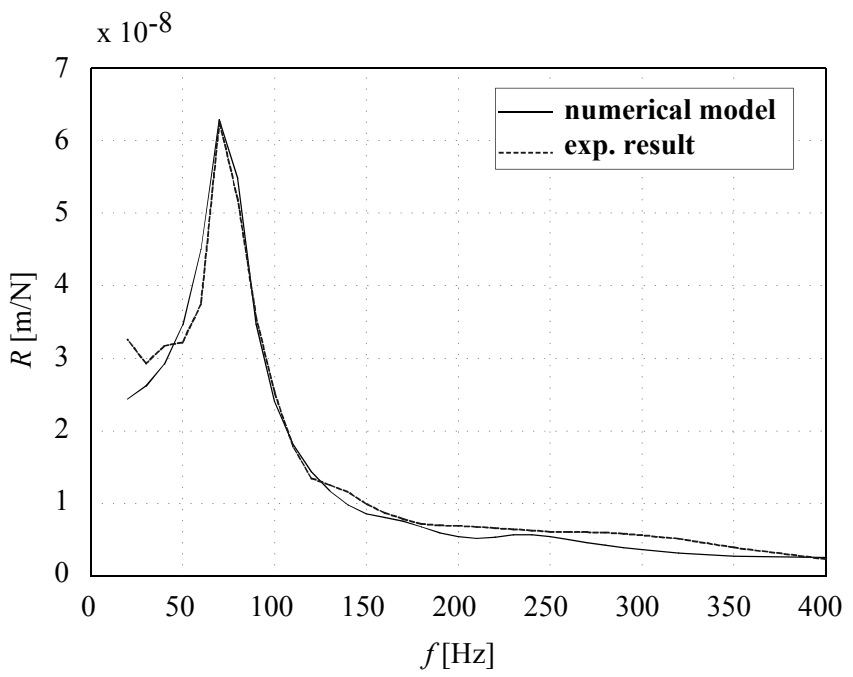

Fig 4. Comparison of the numerical receptance and the experimental receptance.

The concordance between the numerical and experimental result is satisfactory. In fact, these measurements and comparison have been of great interest, as this type of railway track is one of the most currently used in the metropolitan railway of Barcelona. This experimental result demonstrates the validity of the numerical model. According to the results, it can be deduced that the traditional ballasted track has only a natural frequency, this is due to the very high stiffness of the fasteners under the rails.

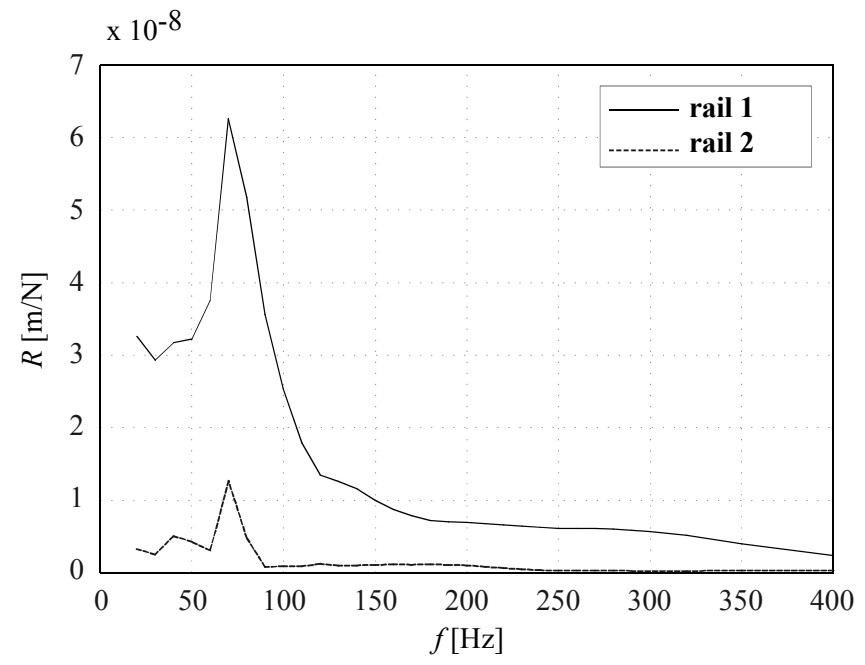

Fig 5. Comparison of the experimental receptance between the two rails.
Finally, in the last figure, the experimental receptance is indicated at the point where the excitation force is applied (rail 1), and the cross receptance is defined in the opposite rail, just in front of the excitation point (rail 2). Again in this case, the low vibration transmission occurring between both rails is experimentally verified.

\section{Conclusions}

There is a good concordance between the numerically calculated receptances, and those obtained experimentally. This result confirms the validity of the numerical model.

The experimental result, like the numerical one, confirms that the vibration transmission, from one rail to another through the track superstructure, is weak.

After the comparison between experimental and numerical results, we found that the numerical model facilitate the analysis of the main factors involved in the vibrations generation in the wheel-rail contact area and their transmission to the environment.

\section{References}

[1] D. Thompson, C. Jones, Noise and Vibration from Railway Vehicles, In Handbook of Railway Vehicle Dynamics, CRC press, Taylor \& Francis Group, Boca Raton, USA, 2006.

[2] S. Cardona, J. Tejedo, Instalación de monitorizado por vibraciones para ferrocarriles metropolitanos. Anales de Ingeniería Mecánica. Volume 01(1988), $327-330$.

[3] J. Martínez, S. Cardona, M.A, De los Santos, J. Otero, Identification of wheel profile irregularities by means of the measured vibrations due to the passage of a train, Proceedings of the TMT 2007 Conference, Hammamet, Tunisia, 2007, 715-718.

[4] J. Otero, J. Martínez, M. A, De Los Santos, S. Cardona, A mathematical model to study railway track dynamics for prediction of vibration levels generated by rail vehicles, Journal of Rail and Rapid Transit. Volume 226(1) (2012), 62-71.

[5] A. Zougari, J. Martínez, S. Cardona, Obtención de la respuesta vibratoria vertical de vías férreas mediante modelos numéricos. Revista Iberoamericana de Ingeniería Mecánica. Volume 17 (2013), 03-15.

[6] A. Zougari, J. Martínez, S. Cardona, Vibration response of a railway track obtained using numerical models based on FEM, MATEC Web Volume 1(2012), Marrakech, Morocco, 10001 1-4.

[7] A. Zougari, Study of the vibratory behaviour of railway tracks by numerical simulation, Thesis, Universitat Politècnica de Catalunya, 2014.

[8] A. Zougari, J. Martínez, S. Cardona, Numerical models of railway tracks for obtaining their frequency response. Comparison with analytical results and experimental measurements, Journal of Vibroengineering, Volume 18 (2016), 1104-1114.

[9] Ansys Inc, Ansys Release19 Multiphysics, Documentation Manual. EEUU, 2018. 